\title{
Self-Crystallized Multifunctional 2D Perovskite for Efficient and Stable Perovskite Solar Cells
}

\author{
Hobeom Kim, Mingyuan Pei, Yonghui Lee, Albertus A. Sutanto, Sanghyun Paek, \\ Valentin I. E. Queloz, Aron J. Huckaba, Kyung Taek Cho, Hyung Joong Yun, \\ Hoichang Yang, and Mohammad Khaja Nazeeruddin*
}

Recently, perovskite solar cells (PSC) with high power-conversion efficiency (PCE) and long-term stability have been achieved by employing 2D perovskite layers on 3D perovskite light absorbers. However, in-depth studies on the material and the interface between the two perovskite layers are still required to understand the role of the 2D perovskite in PSCs. Self-crystallization of 2D perovskite is successfully induced by deposition of benzyl ammonium iodide (BnAI) on top of a 3D perovskite light absorber. The self-crystallized 2D perovskite can perform a multifunctional role in facilitating hole transfer, owing to its random crystalline orientation and passivating traps in the $3 \mathrm{D}$ perovskite. The use of the multifunctional 2D perovskite (M2P) leads to improvement in PCE and long-term stability of PSCs both with and without organic hole transporting material (HTM), 2,2',7,7'-tetrakis-(N,N-di-pmethoxyphenyl-amine)-9,9'-spirobifluorene (spiro-OMeTAD) compared to the devices without the M2P.

\section{Introduction}

Organic-inorganic metal halide perovskites are one of the most promising materials with excellent optoelectronic properties, such as high absorption coefficient, long-range diffusion length, and high mobility of charge carriers, and efficient dissociation of photoinduced excitons. ${ }^{[1-6]}$ On the basis of such properties, extensive researches on perovskite solar cells (PSCs) have been performed and recently resulted in the certified power conversion efficiency (PCE) of 25.2\%. ${ }^{[7]}$ Nevertheless, 3D perovskite

Dr. H. Kim, Dr. Y. Lee, A. A. Sutanto, Dr. S. Paek, V. I. E. Queloz,

Dr. A. J. Huckaba, Dr. K. T. Cho, Prof. M. K. Nazeeruddin

Group for Molecular Engineering of Functional Materials

École Polytechnique Fédérale de Lausanne

Sion $\mathrm{CH}-1951$, Switzerland

E-mail: mdkhaja.nazeeruddin@epfl.ch

M. Pei, Prof. H. Yang

Department of Chemical Engineering

Inha University

Incheon 22212, Republic of Korea

Dr. H. J. Yun

Advance Nano Research Group

Korea Basic Science Institute

Daejeon 34133, Republic of Korea

The ORCID identification number(s) for the author(s) of this article can be found under https://doi.org/10.1002/adfm.201910620.

DOI: $10.1002 / \mathrm{adfm} .201910620$ light absorbers have suffered from high defect density at the surfaces and grain boundaries, which can lead to nonradiative recombination and decrease PCEs of PSC. ${ }^{[6,8]}$ Also, the volatile organic cation in the 3D perovskite lattice such as methylammonium $\left(\mathrm{MA}^{+}\right)$and formamidinium $\left(\mathrm{FA}^{+}\right)$degrades the stability of the perovskite itself and lifetime of PSCs. ${ }^{[9,10]}$ In this regard, 2D perovskites have recently received substantial attention as they contain less-volatile bulkier organic cations, which can trigger passivation effect and lead to better water resistance, resulting in higher PCE and extended long-term stability of PSCs. Therefore, the deposition of $2 \mathrm{D}$ perovskite on top of the $3 \mathrm{D}$ perovskite has presented significant enhancement both in PCEs and stability of PSCs because the $3 \mathrm{D} / 2 \mathrm{D}$ perovskite can take advantage of features of 2D perovskite while it can maintain the excellent optoelectronic properties of 3D perovskites. ${ }^{[11-19]}$

In this study, we present the incorporation of self-crystallized multifunctional 2D perovskite (M2P) on top of a 3D perovskite $\left(\mathrm{Cs}_{0.08} \mathrm{FA}_{0.77} \mathrm{MA}_{0.12} \mathrm{PbI}_{2.62} \mathrm{Br}_{0.35}\right)$ light absorber. The self-crystallized M2P can facilitate hole transfer due to its randomly oriented crystalline structure and reduce the trap density in underlying 3D perovskite through a trap passivation effect. Therefore, the introduction of the M2P layer between 3D perovskite light absorber and hole transport material (HTM) in a PSC led to improvement in the PCE from $19.75 \%$ to $20.79 \%$ and long-term stability under simulated continuous sunlight, compared to the device without the M2P layer. Furthermore, we demonstrated the use of M2P as a hole-transporting layer (HTL) in a PSC without using the organic HTM, 2,2',7,7'-tetrakis( $N, N$-di-p-methoxyphenyl-amine)-9,9'-spirobifluorene (spiroOMeTAD), which resulted in PCE of $15.17 \%$, which was greatly higher than PCE of the device without M2P (6.22\%).

\section{Results and Discussion}

We developed layer-by-layer deposited self-crystallized 2D perovskite grown on top of 3D perovskite using a solution of benzylammonium iodide (BnAI) dissolved in isopropanol (IPA), followed by thermal treatment at $100{ }^{\circ} \mathrm{C}$ for $5 \mathrm{~min}$. The deposited $\mathrm{BnAI}$ reacts with an excess of $\mathrm{PbI}_{2}$ present in the perovskite 
a

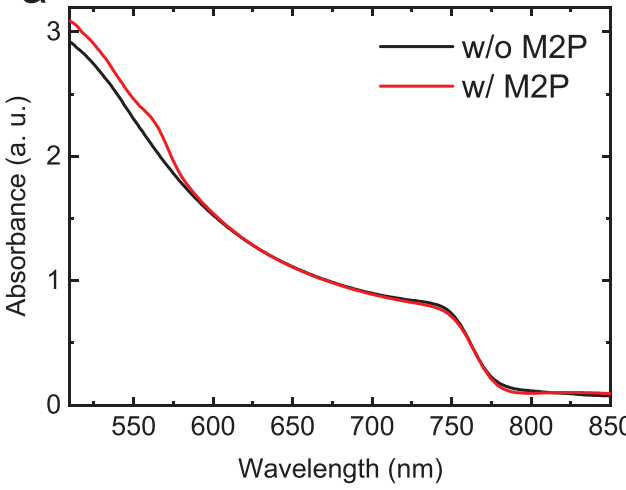

C

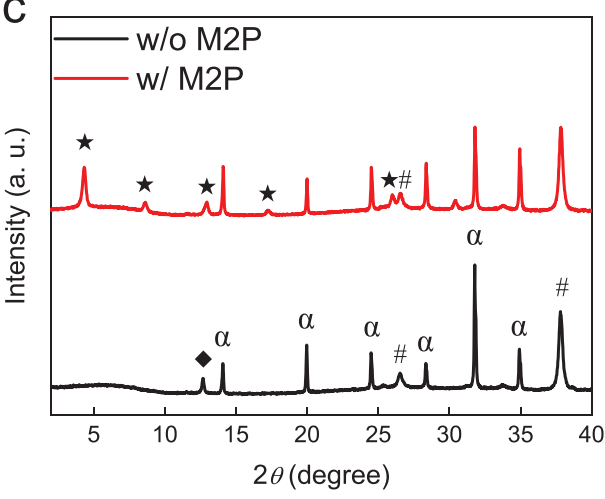

b

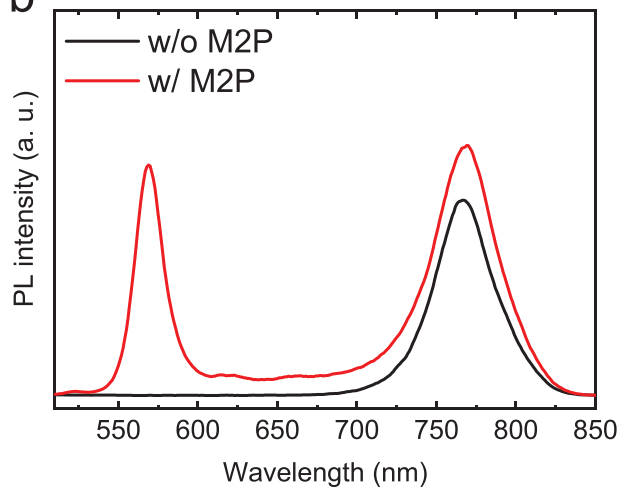

d

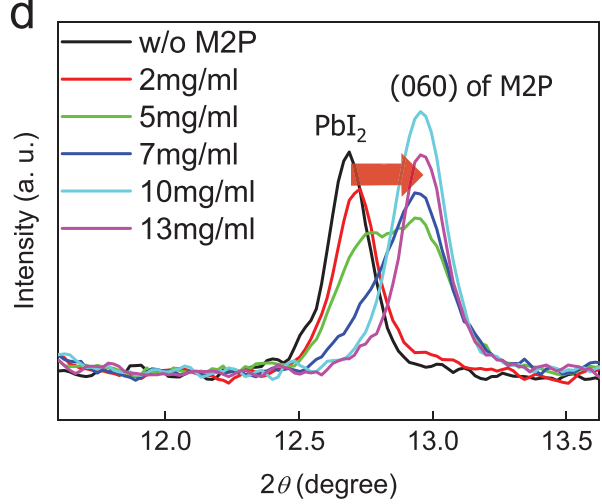

Figure 1. a) UV-vis absorption, b) PL spectra, and c) XRD patterns of 3D perovskite film and the film layered with the M2P. $\alpha$, $\bullet$, \#, and $\star$ denote diffraction peaks corresponding to $3 \mathrm{D}$ perovskite, $\mathrm{Pbl}_{2}$, fluorine-doped tin oxide (FTO), and 2D perovskite, respectively. d) Magnified version of XRD patterns showing the transition of diffraction peak from $\mathrm{Pbl}_{2}$ to $(060)$ of $2 \mathrm{D}$ perovskite as increasing precursor concentration.

composition FAI (1.04 м), $\mathrm{PbI}_{2}(1.19 \mathrm{~m}), \mathrm{MABr}(0.16 \mathrm{~m}), \mathrm{PbBr}_{2}$ $(0.16 \mathrm{M})$, and CsI $(0.10 \mathrm{M})$. The absorption spectrum of the film prior to the deposition of BnAI solution was typical of pure 3D perovskite with an absorption onset of $780 \mathrm{~nm}$ (Figure 1a). In the film with the M2P layer, an additional excitonic peak was observed at an absorption onset of $585 \mathrm{~nm}$, which originated from the self-crystallized M2P. ${ }^{[17,20]}$ The absorption peak intensity of the M2P became stronger with increasing concentration of the BnAI solution while the absorbance onset of the $3 \mathrm{D}$ perovskite remained unchanged (Figure S1, Supporting Information). We also characterized steady-state photoluminescence (PL) of the films to confirm the M2P formation (Figure 1b). The films were excited with $405 \mathrm{~nm}$ light from the top side of the film, and we observed a clear difference in PL between films with and without M2P. While the pristine 3D perovskite film showed an emission peak only at $767 \mathrm{~nm}$, PL spectrum of the film with BnAI treatment had an additional strong emission peak at $568 \mathrm{~nm}$, which can be attributed to the M2P. ${ }^{[12,21]}$ It is worth noting that the formation of the M2P led to an increase in the $3 \mathrm{D}$ perovskite PL intensity, which can be ascribed to a defect passivation effect by the M2P reducing nonradiative recombination in the $3 \mathrm{D}$ perovskite. ${ }^{[11,12]}$ We observed a tradeoff between the intensities of the two PL peaks with varying concentrations of M2P precursor solution (Figure S2a, Supporting Information). As the concentration of the precursor solution was increased, the PL intensity of the M2P increased but that of the $3 \mathrm{D}$ perovskite decreased due to the increasing thickness (and light absorption) of M2P on top of the 3D perovskite. The use of the M2P caused a slight increase in the full-width half maximum (FWHM) of the 3D perovskite PL peak from 45 to $47 \mathrm{~nm}$ (Figure S2b,c, Supporting Information). Additionally, the $3 \mathrm{D}$ perovskite PL peak at $767 \mathrm{~nm}$ was gradually redshifted with increasing precursor concentration, up to $772 \mathrm{~nm}$. These results may be associated with the layer-edge states emission of Ruddlesden-Popper perovskites. ${ }^{[22]}$ When the films were excited from the bottom (glass) side, the spectra did not contain signals corresponding to 2D perovskite in the low wavelength region (Figure S3, Supporting Information), which indicated that the M2Ps were present on top of the 3D perovskite only, and were not excited by the incident laser due to the high extinction coefficient of $3 \mathrm{D}$ perovskite. ${ }^{[14]}$ We also performed transient PL measurement of the films and the PL decay curves were fitted to a biexponential decay function (Figure S4, Supporting Information). The PL average lifetime $\tau_{\text {Ave }}$ was significantly improved in the M2P (7 mg mL $\left.\mathrm{m}^{-1}\right)$ layered 3D perovskite $\left(\tau_{\mathrm{Ave}}=94.93 \mathrm{~ns}\right)$ compared to the $3 \mathrm{D}$ perovskite film without the M2P ( $\left.\tau_{\mathrm{Ave}}=68.12 \mathrm{~ns}\right)$. This implies that the use of M2P can reduce nonradiative recombination by effectively passivating defects of the underlying 3D perovskite. We summarized the detailed decay parameters based on biexponential decay function in Table S1 in the Supporting Information.

1D X-ray diffraction (XRD) patterns of the films also confirmed the presence of the M2P. The film without the M2P showed a typical 3D perovskite pattern and excess $\mathrm{PbI}_{2}$ as 
denoted in Figure 1c. ${ }^{[23-25]}$ On the other hand, the 3D perovskite/M2P film had new diffraction peaks at $4.3^{\circ}, 8.6^{\circ}, 13.0^{\circ}$, $17.3^{\circ}$, and $26.0^{\circ}$, respectively corresponding to (020), (040), (060), (080), and (0k0) of $2 \mathrm{D}$ perovskite, $\mathrm{BnA}_{2} \mathrm{ZPb}_{2} \mathrm{X}_{7}$, where $\mathrm{Z}$ is a combination of the three cations FA, MA, and Cs, and $\mathrm{X}$ is a combination of I and $\mathrm{Br}^{[20]}$ Interestingly, we observed a diffraction peak transition with increasing M2P precursor concentration (Figure 1d), in which the intensity of the $\mathrm{PbI}_{2}$ peak at $12.7^{\circ}$ was decreased and finally disappeared while a new peak appeared at $13.0^{\circ}$, which was ascribed to $(060)$ of $\mathrm{BnA}_{2} \mathrm{ZPb}_{2} \mathrm{X}_{7}$. This indicates that the precursor, BnAI, reacted with the excess $\mathrm{PbI}_{2}$ observed in the XRD patterns resulting in the formation of the $\mathrm{M} 2 \mathrm{P}, \mathrm{BnA}_{2} \mathrm{ZPb}_{2} \mathrm{X}_{7}$ as in Equation (1)

$2 \mathrm{PbI}_{2}+2 \mathrm{BnA}^{+}+\mathrm{Z}^{+}+3 \mathrm{X}^{-} \rightarrow \mathrm{BnA}_{2} \mathrm{ZPb}_{2} \mathrm{X}_{7}$

We observed the film morphology of the perovskite films using top-view scanning electroscopic microscopy (SEM) images (Figure 2a,b). While the 3D pristine film had compact grains with clearly visible grain boundaries, the formation of M2P on the top surface rendered the film smoother and homogeneous. The sparsely distributed bright white grains attributed to the unreacted $\mathrm{PbI}_{2}$ disappeared upon the application of the M2P precursor, which also supports the claim of a chemical reaction between $\mathrm{PbI}_{2}$ and $\mathrm{BnAI}$ resulting in the formation of M2P (Equation 1; Figure S5, Supporting Information). ${ }^{[14,26,27]}$ The observed changes in surface morphology can be attributed to the reconstruction of perovskite during the formation of the M2P on the top of the $3 \mathrm{D}$ perovskite. ${ }^{[12]}$ Crosssectional SEM images showed the formation of an additional layer, the M2P, on top of the 3D perovskite (Figure S6, Supporting Information). The thickness of the $3 \mathrm{D}$ perovskite layer was $\approx 600 \mathrm{~nm}$, and the thickness of the M2P on top of the $3 \mathrm{D}$ perovskite was $\approx 50 \mathrm{~nm}$ when $7 \mathrm{mg} \mathrm{mL} \mathrm{m}^{-1}$ BnAI solution was used (Figure S7, Supporting Information). The thickness of the M2P increased to $\approx 70 \mathrm{~nm}$ with the use of a $13 \mathrm{mg} \mathrm{mL}^{-1} \mathrm{BnAI}$ solution.

To understand how the deposition of the M2P on 3D perovskite affected the nature of the chemical bonds, we performed X-ray photoemission spectroscopy (XPS) on the films. The $\mathrm{C} 1 \mathrm{~s}$ spectrum of the pristine film without the M2P showed three main peaks at 284.9, 286.9, and $288.5 \mathrm{eV}$ which can be assigned to the $\mathrm{C}-\mathrm{C}, \mathrm{C}-\mathrm{N}$, and $\mathrm{C}=\mathrm{O}$ bond, respectively (Figure $2 \mathrm{c}$ ). ${ }^{[13]}$ The deposition of the M2P with the more concentrated precursor solutions led to an increase in the intensity of $\mathrm{C}-\mathrm{C}$ and $\mathrm{C}-\mathrm{N}$, which can be attributed to the chemical structure of BnA including benzene and higher portion of $\mathrm{C}-\mathrm{N}$ moieties in the $2 \mathrm{D}$ perovskite than the 3D perovskite. The decrease in $\mathrm{C}=\mathrm{O}$ which can be generated by the decomposition of the 3D perovskite suggests that the M2P can protect the underlying $3 \mathrm{D}$ perovskite against oxygen and moisture. ${ }^{[6,13]}$ In the $\mathrm{N} 1$ s spectra, the $3 \mathrm{D}$ perovskite film showed a peak at $400.8 \mathrm{eV}$ which arose from $-\mathrm{NH}_{2}$ of FA while the M2P deposited films led to the formation of another peak at $402.3 \mathrm{eV}$, originating from $-\mathrm{NH}_{3}{ }^{+}$of BnA (Figure 2d). ${ }^{[28]}$

Analysis of grazing incidence X-ray diffraction (GIXD) presented interesting crystalline structural features with varying M2P precursor concentration (Figure 3a). In general, all the films had randomly oriented 3D perovskites as determined by Debye-Scherrer rings. The deposition of $2 \mathrm{mg} \mathrm{mL}^{-1} \mathrm{BnAI}$ on top of the $3 \mathrm{D}$ perovskite presented a new signal at scattering vector along the $Q_{z}$ axis $\left(Q=0.317 \AA^{-1}\right)$, indicating that $(020)$ crystal planes in the $2 \mathrm{D}$ perovskite were preferentially oriented parallel to the surface. On the other hand, increasing the precursor concentration led to the growth of $2 \mathrm{D}$ perovskite in a rather random orientation. Based on this result, we present a schematic showing horizontally aligned 2D perovskite resulting from the deposition of $2 \mathrm{mg} \mathrm{mL}^{-1} \mathrm{BnAI}$ and randomly oriented 2D perovskites grown by the use of more concentrated precursor solutions (Figure 3b). Horizontally oriented 2D perovskites can impede efficient hole transport due to the unfavorable alignment of insulating organic slabs, while randomly oriented 2D perovskites can facilitate hole transport by increasing the possibility of contact between adjacent inorganic slabs. ${ }^{[29]}$

To verify the improved hole transfer and the passivation effect by introducing the M2P, we designed and characterized hole-only devices (HODs) with a structure of ITO/self-organized
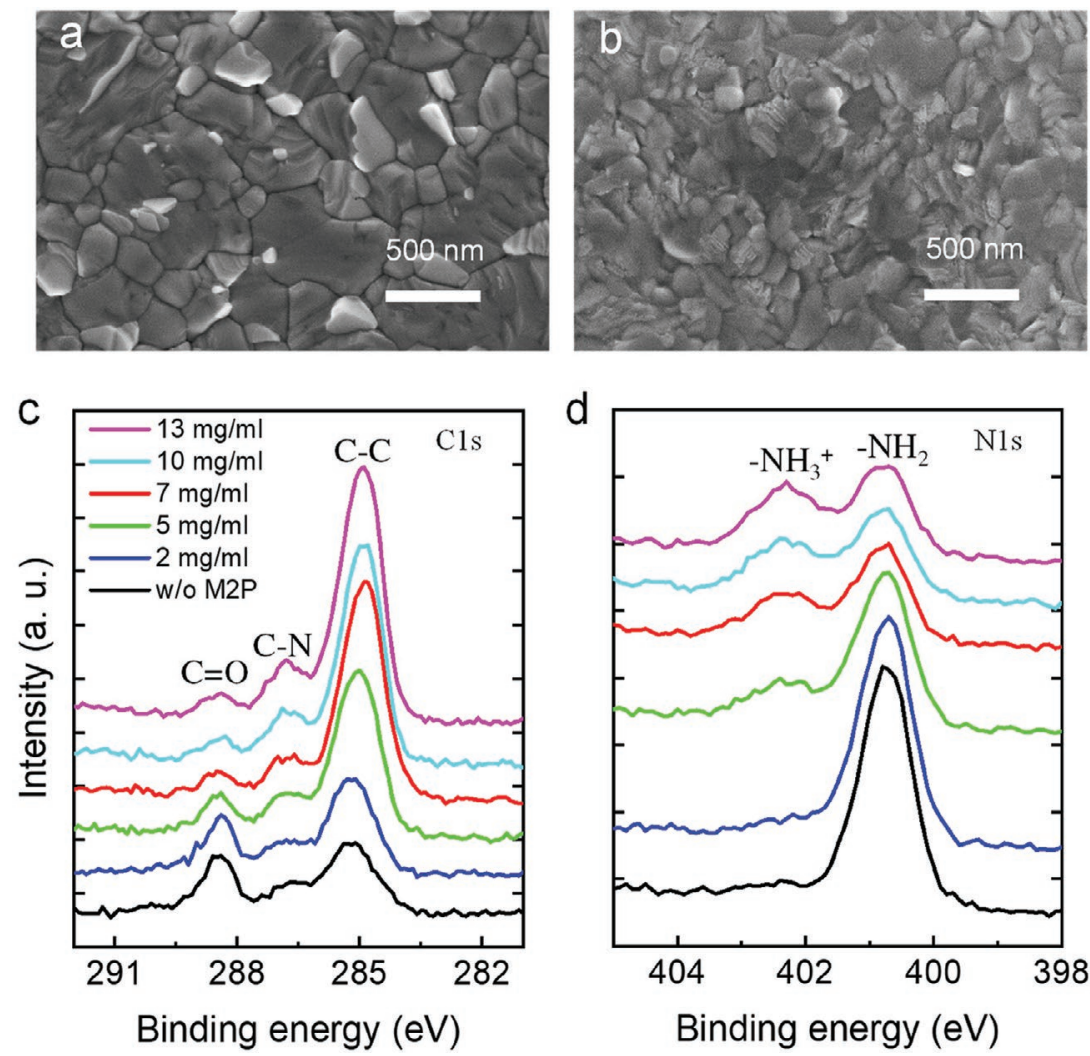

Figure 2. Top-view SEM images of a) the 3D perovskite film and b) the film layered with the M2P. Core level XPS spectra of c) C 1s and d) N 1s for the perovskite films without and with the $\mathrm{M} 2 \mathrm{P}$ of various concentrations. 

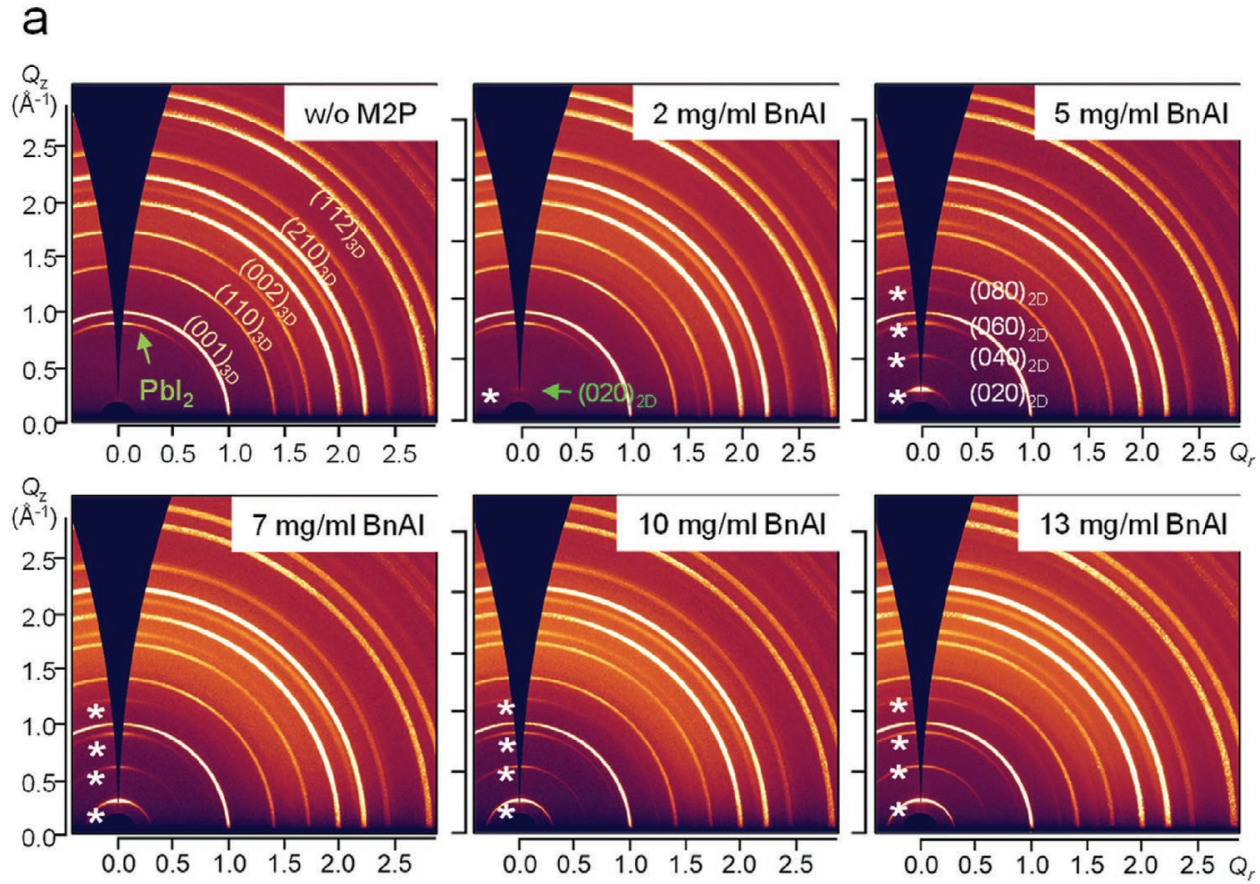

b
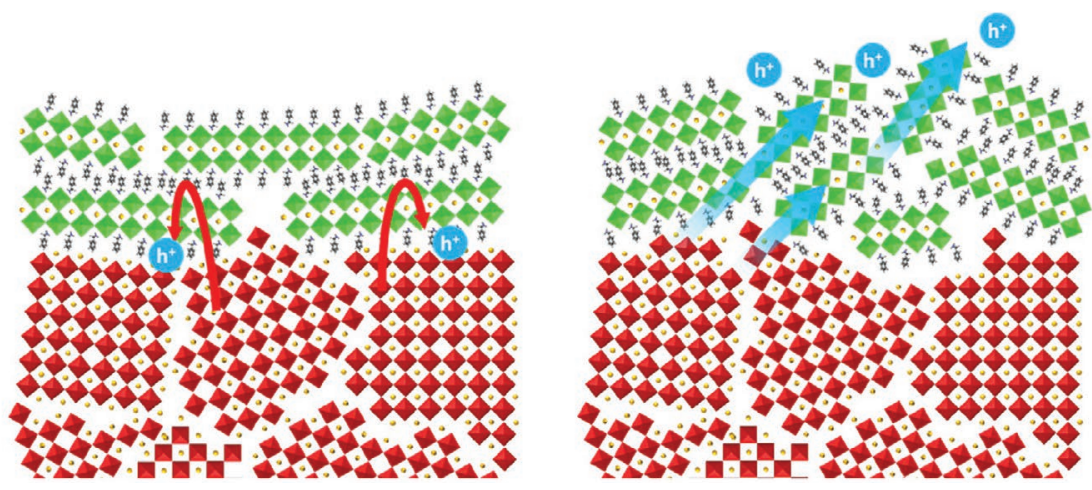

Figure 3. a) GIXD 2D patterns of perovskite films according to the condition of the M2P. b) Schematic of crystalline structures of M2Ps on 3D perovskite.

buffer hole injection layer (Buf-HIL) (50 nm) which consists of PEDOT:PSS and perfluorinated ionomer/3D perovskite (600 nm)/M2P/Spiro-OMeTAD (200 nm)/Au (70 nm). The current of the device increased with increasing concentration of M2P precursor solution to $7 \mathrm{mg} \mathrm{mL}^{-1}$, which indicates that the M2P facilitates hole transfer and transport (Figure 4a; Figure S8, Supporting Information). However, the use of precursor solutions with a concentration higher than $7 \mathrm{mg} \mathrm{mL}$ led to a decrease in the hole current, implying that the M2P with an excess thickness can impede efficient charge transfer possibly due to a large amount of insulating organic slabs in the structure. To confirm the capability of the M2P as a holetransfer facilitator, we calculated hole mobility $\left(\mu_{\mathrm{h}}\right)$ of the perovskites by fitting $J-V$ curves in space-charge-limited current (SCLC) regime of HODs to the Mott-Gurney equation (Figure 4b; Figure S8, Supporting Information)

$J=\frac{9 \varepsilon \varepsilon_{0} \mu_{h} V^{2}}{8 L^{3}}$ where $J$ is dark current density of a device, $V$ is applied voltage, $L$ is thickness of perovskite, $\varepsilon$ is relative dielectric constant (here, we used 46.9), ${ }^{[30]}$ and $\varepsilon_{0}$ is the vacuum permittivity. ${ }^{[31]}$ The $\mu_{\mathrm{h}}$ of devices had the same trend as the $J-V$ characteristics of the devices. The $\mu_{\mathrm{h}}$ of perovskite with the M2P $\left(7 \mathrm{mg} \mathrm{mL}^{-1}\right)$ was $0.6469 \mathrm{~cm}^{2} \mathrm{~V}^{-1} \mathrm{~s}^{-1}$, which is 5.7 times higher than the $\mu_{\mathrm{h}}$ of perovskite without the M2P $\left(0.1135 \mathrm{~cm}^{2} \mathrm{~V}^{-1} \mathrm{~s}^{-1}\right)$. However, increasing the M2P precursor concentration above $7 \mathrm{mg} \mathrm{mL}^{-1}$ significantly degraded $\mu_{\mathrm{h}}$ to $0.2326 \mathrm{~cm}^{2} \mathrm{~V}^{-1} \mathrm{~s}^{-1}$ for $10 \mathrm{mg} \mathrm{mL}^{-1}$ and $0.1285 \mathrm{~cm}^{2} \mathrm{~V}^{-1} \mathrm{~s}^{-1}$ for $13 \mathrm{mg} \mathrm{mL}^{-1} \mathrm{M} 2 \mathrm{P}$ precursor. This result can be attributed to the same reason as the lowered current of HODs associated with the amount of insulating organic slabs in the 2D perovskite. We summarized the $\mu_{\mathrm{h}}$ of each HOD in Table S2 in the Supporting Information. Figure $4 \mathrm{~b}$ shows a shift in trapfilled limit voltage $\left(V_{\mathrm{TFL}}\right)$ with the incorporation of the M2P at which point there is a transition of $J-V$ behavior from Ohmic to the trap-filling limited (TFL) regime. Therefore, we evaluated the passivation effect of the M2P by estimating trap density $\left(n_{\mathrm{t}}\right)$ of the perovskites according to the following Equation ${ }^{[32]}$ 
a

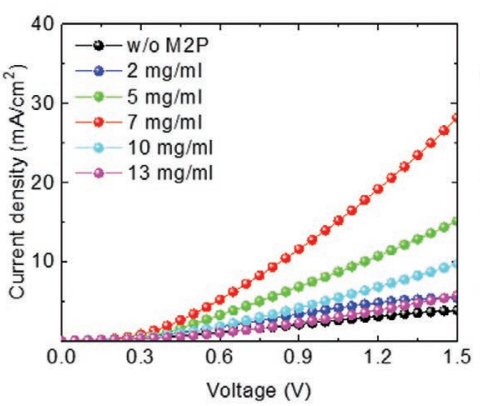

C

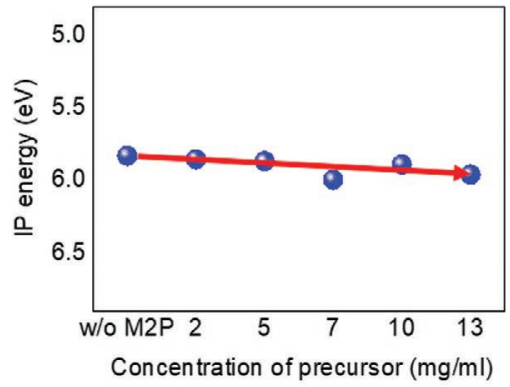

d

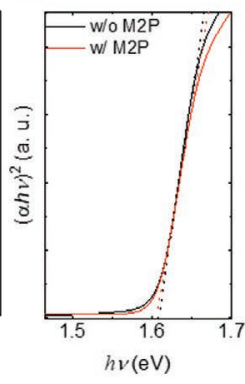

b

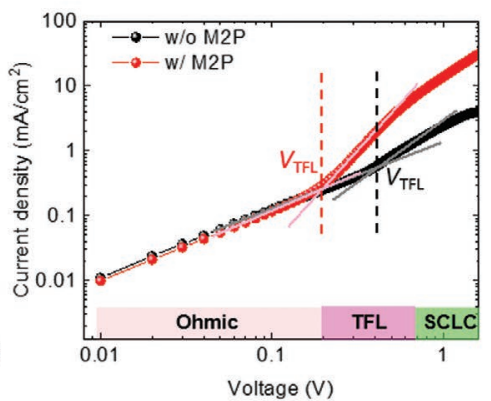

e

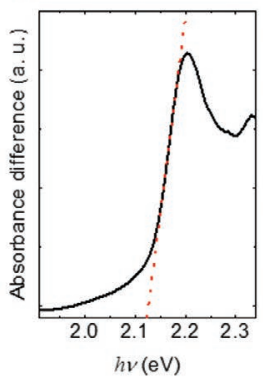

f

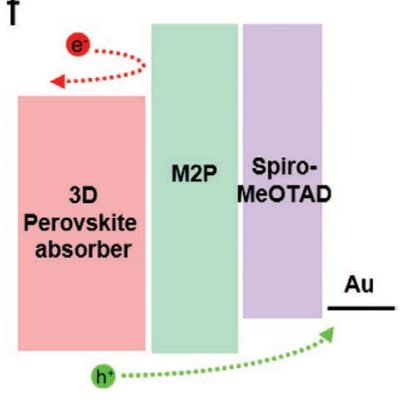

Figure 4. a) $J-V$ curves of HODs with various conditions of M2P. b) $J-V$ curves of HODs with and without M2P (7 mg mL $\left.\mathrm{m}^{-1}\right)$ showing a shift in $V_{\text {TFL }}$. c) lonization potential (IP) energy of perovskite films with various conditions of M2P on top of 3D perovskite. d) Tauc plot of perovskite film with and without M2P e) Difference in absorbance of 3D perovskite and M2P deposited 3D perovskite. f) Schematic energy band diagram showing efficient hole transfer and electron blocking by M2P.

$V_{\mathrm{TFL}}=n_{t} \frac{e L^{2}}{2 \varepsilon \varepsilon_{0}}$

where $e$ is the elementary charge of the electron. The HOD with M2P $\left(7 \mathrm{mg} \mathrm{mL}^{-1}\right)$ had a significantly lower $V_{\mathrm{TFL}}(0.198 \mathrm{~V})$ than that of the device without M2P $(0.418 \mathrm{~V})$. Thus, we obtained $n_{\mathrm{t}}=2.43 \times 10^{15} \mathrm{~cm}^{-3}$ for the M2P deposited 3D perovskite and $n_{\mathrm{t}}=6.02 \times 10^{15} \mathrm{~cm}^{-3}$ for the 3D perovskite without M2P. This result indicates that $\mathrm{M} 2 \mathrm{P}$ can passivate the trap states of underlying 3D perovskite, thereby reduce the loss of charge carriers.

We investigated the energy levels of $3 \mathrm{D}$ perovskite and M2P (7 mg mL $\mathrm{mL}^{-1}$ ). Ultraviolet photoemission spectroscopy (UPS) analysis presented a minute increase in surface ionization potential (IP) energy with increasing concentration of the M2P precursor (Figure 4c; Figure S9, Supporting Information). The Tauc plot analysis of $3 \mathrm{D}$ perovskite with and without M2P resulted in the same bandgap energy as $1.61 \mathrm{eV}$ (Figure $4 \mathrm{~d}$ ), and we found the bandgap energy of the M2P as $2.12 \mathrm{eV}$ by defining the onset of its absorption excitonic peak and subtracting absorption spectrum of the $3 \mathrm{D}$ perovskite from that of the 3D perovskite/M2P (Figure 4e). Therefore, we constructed an energy level diagram in which the M2P deposited on 3D perovskite can efficiently block undesirable electron back transfer from the 3D perovskite to spiro-OMeTAD but facilitate hole transfer (Figure 4f). ${ }^{111]}$

We applied the developed M2P with various precursor concentrations into PSCs without spiro-OMeTAD (FTO/compact$\mathrm{TiO}_{2} /$ mesoporous $\mathrm{TiO}_{2} / \mathrm{SnO}_{2} / 3 \mathrm{D}$ perovskite/M2P/Au) to find the optimal precursor concentration and achieve the highest
PCE (Figure 5a). While the PSCs without the M2P showed the lowest value with an average PCE of $3.81 \%$, the average PCE increased up to $13.50 \%$ when using the $7 \mathrm{mg} \mathrm{mL}^{-1} \mathrm{M} 2 \mathrm{P}$ precursor solution but decreased with further increase in the precursor concentration. We also compared each photovoltaic parameter (e.g., $V_{\mathrm{oc}}, J_{\mathrm{sc}}$, and FF) as a function of the precursor concentration (Figure S10, Supporting Information). The $V_{\text {oc }}$ of the devices was saturated from using $7 \mathrm{mg} \mathrm{mL}^{-1}$ precursor solution, which indicates that the built-in potential reached a maximum, due to the full coverage of the M2P. On the other hand, the $J_{\mathrm{sc}}$ and FF had the same trend according to the precursor concentration; the decrease in both $J_{\mathrm{sc}}$ and FF at high M2P thickness can be attributed to the increasing amount of insulating organic slab in the M2Ps, which can hinder efficient hole transport. Therefore, the champion device with the M2P (7 mg mL $\mathrm{mb}^{-1}$ ) showed a PCE of $15.17 \%, V_{\text {oc }}$ of $0.932 \mathrm{~V}, J_{\mathrm{sc}}$ of $23.48 \mathrm{~mA} \mathrm{~cm}^{-2}$, and $\mathrm{FF}$ of $69.3 \%$ while the device without the M2P showed inferior photovoltaic characteristics with a PCE of $6.22 \%, V_{\text {oc }}$ of $0.852 \mathrm{~V}, J_{\text {sc }}$ of $22.76 \mathrm{~mA} \mathrm{~cm}^{-2}$, and FF of $32.1 \%$ in the best cell (Figure 5b). This dramatic improvement in device performance implies that the M2P as it is can function as an HTL. In addition, the incorporation of the M2P greatly improved $J-V$ hysteresis behavior of the device depending on the voltage sweep direction compared to the device without the M2P (Figure S11, Supporting Information).

Lastly, we employed the optimized M2P for the device with spiro-OMeTAD (FTO/compact-TiO $2 /$ mesoporous $\mathrm{TiO}_{2} /$ $\mathrm{SnO}_{2} / 3 \mathrm{D}$ perovskite/M2P/spiro-OMeTAD/Au). The device with the optimized M2P achieved PCE of $20.79 \%, V_{\text {oc }}$ of $1.078 \mathrm{~V}, J_{\text {sc }}$ 
a

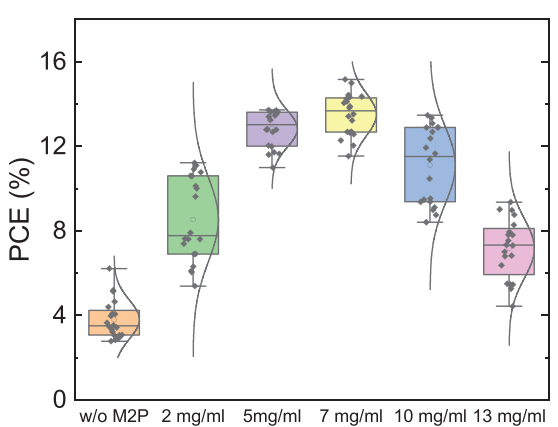

C

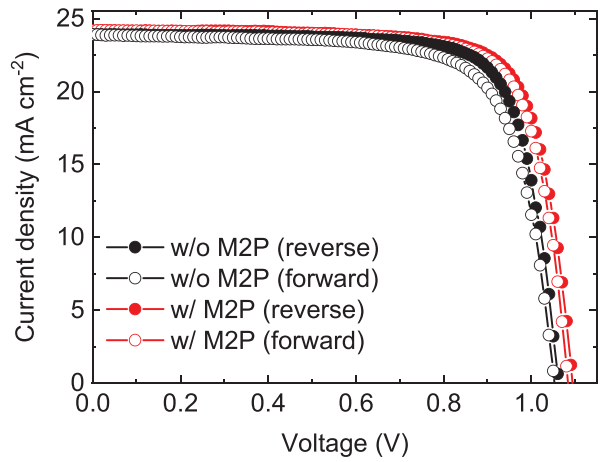

b

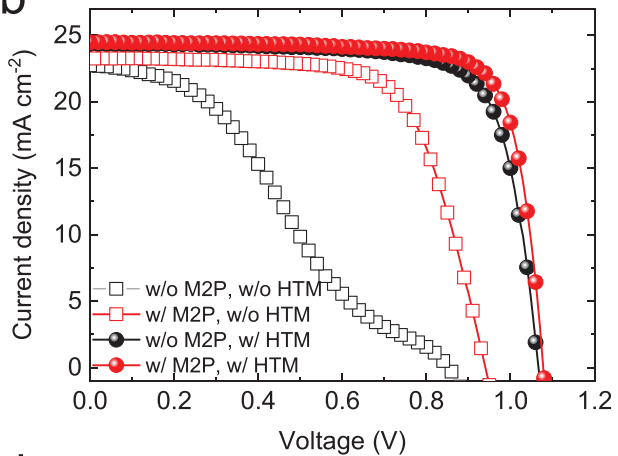

d

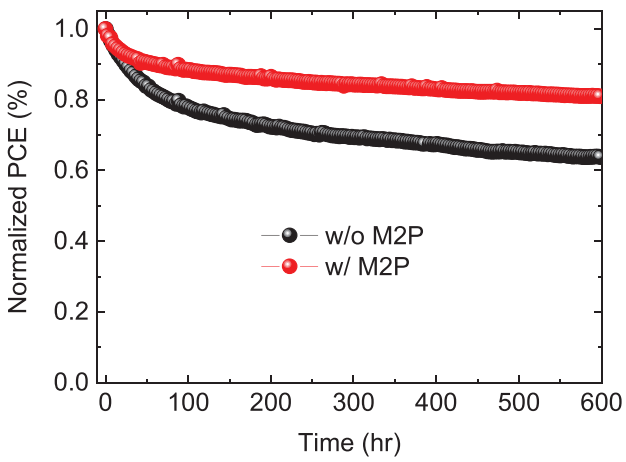

Figure 5. a) Statistics of PCEs of PSCs without spiro-OMeTAD according to various conditions of M2P precursor solution. b) J-V curves of champion PSCs according to M2P and spiro-OMeTAD conditions c) J-V curves of PSCs with spiro-OMeTAD according to M2P condition under reverse and forward scan. d) The long-term stability of PSCs with spiro-OMeTAD according to M2P condition under illumination and an inert (Ar) atmosphere.

of $24.48 \mathrm{~mA} \mathrm{~cm}^{-2}$, and FF of $78.8 \%$ while the PSCs without the M2P exhibited PCE of $19.75 \%, V_{\text {oc }}$ of $1.066 \mathrm{~V}, J_{\mathrm{sc}}$ of $24.36 \mathrm{~mA} \mathrm{~cm}^{-2}$, and FF of $76.0 \%$, (Figure $5 \mathrm{~b}$ ). We presented the statistics of PCE, $V_{\mathrm{oc}}, J_{\mathrm{sc}}$, and FF of the devices in Figure S12 in the Supporting Information. The improvement in the device characteristics can be attributed to the incorporation of the M2P that performs as both a hole-transfer facilitator and a surface trap passivator. Also, the device showed highly stable $J-V$ hysteresis characteristics exhibiting a PCE of $20.32 \%$ and $20.05 \%$ under reverse and forward bias, respectively and resulted in a hysteresis index $(\mathrm{HI})$ of $1.3 \%$, defined as $\frac{\mathrm{PCE}_{\text {reverse }}-\mathrm{PCE}_{\text {forward }}}{P C E_{\text {rerse }}}$ (Figure 5c). ${ }^{[33,34]}$ In contrast, the device without the M2P resulted in a significantly higher $\mathrm{HI}$ as $5.6 \%$ based on PCE of $19.49 \%$ and $18.4 \%$ under reverse and forward bias, respectively. The use of the M2P also led to an improvement in device stability. Maximum power point tracking of devices under constant illumination in inert (Ar) atmosphere showed that PCE of the PSC using the M2P maintained over $80 \%$ of its initial PCE until $600 \mathrm{~h}$ while the device without the M2P had $64 \%$ of its initial PCE at $600 \mathrm{~h}$ (Figure 5d). We also monitored the PCEs of the devices stored under controlled ambient conditions (relative humidity $<10 \%$ and room temperature). The PCE of the device using the M2P decreased from $20.52 \%$ to $18.65 \%$ maintaining $91 \%$ of the initial PCE after being stored for over 6 months, while that of the device without the M2P decreased from $19.58 \%$ to $16.96 \%$ keeping $87 \%$ of the initial PCE for the same period (Figure S13, Supporting Information).

\section{Conclusion}

In conclusion, we developed a multifunctional 2D perovskite, $\mathrm{BnA}_{2} \mathrm{ZPb}_{2} \mathrm{X}_{7}$ that facilitates hole transfer and passivates surface trap states of the underlying $3 \mathrm{D}$ perovskite in PSCs, which enabled the device to achieve a champion PCE of $20.79 \%$. The increase in the PL intensity and the reduced trap density evidenced that the M2P layer can act as an effective passivating material. Furthermore, we found that randomly oriented inorganic slabs within the M2P can facilitate hole transfer presenting the improved hole current of HODs and $\mu_{\mathrm{h}}$ of perovskite. Lastly, the introduction of the M2P in PSCs significantly extended the device operating lifetime compared to devices without the M2P due to the more stable nature of $2 \mathrm{D}$ perovskites in comparison to $3 \mathrm{D}$ perovskites. Also, we highlight the strategy of using 2D perovskite as an HTL in hopes of paving a way for future research in the field of PSCs.

\section{Experimental Section}

Materials: Formamidinium iodide (FAI), methylammonium bromide $(\mathrm{MABr})$, and $\mathrm{BnAl}$ were purchased from GreatCell Solar. Lead iodide $\left(\mathrm{Pbl}_{2}\right)$ and lead bromide $\left(\mathrm{PbBr}_{2}\right)$ were purchased from TCl. Cesium iodide (Csl) was purchased from abcr $\mathrm{GmbH}$. Dimethylformamide (DMF) (99.9\%, Acros) and dimethyl sulfoxide (DMSO) (99.9\% Acros).

Solar Cell Fabrication: FTO glass substrates (Nippon sheet glass) were cleaned with acetone and IPA, sequentially. A compact $\mathrm{TiO}_{2}$ layer 
was deposited by spray pyrolysis method on the FTO substrate followed by thermal annealing at $450{ }^{\circ} \mathrm{C}$ for $30 \mathrm{~min}$. The precursor solution was prepared by diluting titanium diisopropoxide (Sigma-Aldrich) in ethanol $(0.6 \mathrm{~mL}: 9 \mathrm{~mL})$. To prepare a mesoporous $\mathrm{TiO}_{2}$ layer, $\mathrm{TiO}_{2}$ paste (Greatcell Solar 30 NR-D) was diluted in ethanol $\left(0.117 \mathrm{~g} \mathrm{~mL}^{-1}\right)$ and spin coated it at $5000 \mathrm{rpm}$ for $20 \mathrm{~s}$ followed by sintering at $500{ }^{\circ} \mathrm{C}$ for $30 \mathrm{~min}$. The following $\mathrm{SnO}_{2}$ layer was prepared by spin-coating a precursor solution of $\mathrm{SnCl}_{4}$ (Acros) dissolved in water as $0.1 \mathrm{M}$ and annealed at $190{ }^{\circ} \mathrm{C}$ for $1 \mathrm{~h}$. Then, the substrates were transferred into a glove box to deposit the perovskite and HTL. The lead excess perovskite precursor solution was prepared by mixing FAI (1.04 M), $\mathrm{Pbl}_{2}(1.19 \mathrm{M})$, $\operatorname{MABr}(0.16 \mathrm{M}), \mathrm{PbBr}_{2}(0.16 \mathrm{M})$, and $\mathrm{Csl}(0.10 \mathrm{M})$ in a mixed solvent of DMF:DMSO = 4:1 (volume ratio). The perovskite precursor solution was spin coated at $2000 \mathrm{rpm}$ for $10 \mathrm{~s}$ followed by $5000 \mathrm{rpm}$ for $30 \mathrm{~s}$. During the second step of the spin-coating, $100 \mu \mathrm{L}$ of chlorobenzene was dropped on the substrate. The films were annealed at $100{ }^{\circ} \mathrm{C}$ for $60 \mathrm{~min}$. After cooling down the substrates, $100 \mu \mathrm{L}$ of BnAl solution with various concentrations $\left(2,5,7,10,13 \mathrm{mg} \mathrm{mL}^{-1}\right)$ was spin coated on the perovskite film at $4000 \mathrm{rpm}$ for $20 \mathrm{~s}$ to form the multifunctional 2D perovskite (M2P). The films were additionally annealed at $100{ }^{\circ} \mathrm{C}$ for $5 \mathrm{~min}$. The devices were completed with thermal evaporation of $70 \mathrm{~nm}$-thick gold electrodes.

Characterizations: The absorbance was measured using UV-vis absorption spectrophotometer (PerkinElmer spectrophotometer). $\mathrm{PL}$ of the films was measured using a Flourolog-3 (Horiba Scientific) with an excitation source of $450 \mathrm{~nm}$. XRD analysis was carried out using a Bruker D8 Advance diffractometer. UV-vis absorption, $\mathrm{PL}$, and XRD measurement were conducted in ambient conditions at room temperature with relative humidity below $45 \%$. The prepared films for these characterizations were kept in an inert atmosphere before the measurements. The morphology of films was analyzed by a highresolution scanning electron microscopy (ZEISS Merlin). XPS and UPS were performed by using a photoelectron spectrometer (Kratos Inc., AXIS-Ultra DLD) in collaboration with Korea Basic Science Institute (KBSI). A monochromatic Al-K $\alpha$ line $(1486.6 \mathrm{eV})$ was used for XPS, and $\mathrm{He}$ I radiation $(21.2 \mathrm{eV}$ ) was used for UPS. GIXD was performed on these films at the 6D and 9A beamlines at the Pohang Accelerator Laboratory, South Korea. An incident angle of X-ray $(E=10.03 \mathrm{keV})$ between $0.12^{\circ}$ and $0.15^{\circ}$ below the critical angle $\left(0.18^{\circ}\right)$ was employed and the films were measured under vacuum condition $\left(\approx 10^{-3}\right.$ Torr $)$. For XPS, UPS, and GIXD measurements, the films were kept in an inert atmosphere and rapidly transferred to a vacuum chamber before the measurements within a couple of minutes in order to reduce air exposure time. Solar cell characteristics were evaluated using Oriel solar simulator (Oriel, $450 \mathrm{~W}$, Xenon, AAA class). The light intensity was calibrated with a standard Si reference cell equipped with an IR-cutoff filter (KG3, Newport). Current-voltage (U-V) characteristics of the PSCs were obtained by applying an external bias and reading the current response using Keithley 2400 digital source meter. The voltage scan rate was $100 \mathrm{mV} \mathrm{s}^{-1}$ and the cells were masked with an aperture of $0.16 \mathrm{~cm}^{2}$. Devices were not preconditioned such as light soaking, or a pre-voltage bias applied before starting the measurement. External quantum efficiency was measured using an IQE200B (Oriel) without bias light. The operating stability of the cells was tested in a completely sealed container under continuous illumination in $\mathrm{Ar}$ atmosphere under maximum power point tracking. The LED lamp used in the stability measurement system had a light intensity of $100 \mathrm{~mW}$ $\mathrm{cm}^{-2}$ which was constantly confirmed by a reference Si-photodiode placed in the container. J $V$ characteristics of the devices were recorded on an electronic system using 22-bit delta-sigma analogic to digital converter. A scan rate of $25 \mathrm{mV} \mathrm{s}^{-1}$ with a step of $5 \mathrm{mV}$ was applied and the devices.

\section{Supporting Information}

Supporting Information is available from the Wiley Online Library or from the author.

\section{Acknowledgements}

This project has received funding from the European Union's Horizon 2020 research and innovation programme under grant agreement No. 763989. This publication reflects only the author's views and the European Union is not liable for any use that may be made of the information contained therein. The authors acknowledge the Swiss National Science Foundation (SNSF) funding through the Synergia Grant EPISODE (Grant No. CRSII5_171000). H.Y. thanks for the financial support from the industrial Fundamental Technology Development Program (Grant No. 10051440) funded by the Ministry of Trade, Industry and Energy (MOTIE), Korea.

\section{Conflict of Interest}

The authors declare no conflict of interest.

\section{Keywords}

2D perovskites, hole-transfer facilitators, hole-transporting layers, perovskite solar cells, trap passivation

Received: December 22, 2019

Revised: February 15, 2020

Published online: March 11, 2020

[1] A. Kojima, K. Teshima, Y. Shirai, T. Miyasaka, J. Am. Chem. Soc. 2009, 131, 6050.

[2] E. H. Jung, N. J. Jeon, E. Y. Park, C. S. Moon, T. J. Shin, T.-Y. Yang, J. H. Noh, J. Seo, Nature 2019, 567, 511.

[3] M. Saliba, T. Matsui, J.-Y. Seo, K. Domanski, J.-P. Correa-Baena, M. K. Nazeeruddin, S. M. Zakeeruddin, W. Tress, A. Abate, A. Hagfeldt, M. Grätzel, Energy Environ. Sci. 2016, 9, 1989.

[4] N. J. Jeon, J. H. Noh, W. S. Yang, Y. C. Kim, S. Ryu, J. Seo, S. I. Seok, Nature 2015, 517, 476

[5] H. Kim, K.-G. Lim, T.-W. Lee, Energy Environ. Sci. 2016, 9, 12.

[6] Q. Jiang, Y. Zhao, X. Zhang, X. Yang, Y. Chen, Z. Chu, Q. Ye, X. Li, Z. Yin, J. You, Nat. Photonics 2019, 13, 460.

[7] Best Research-Cell Efficiency Chart | Photovoltaic Research | NREL, https://www.nrel.gov/pv/cell-efficiency.html (accessed: January 2020).

[8] D. Luo, R. Su, W. Zhang, Q. Gong, R. Zhu, Nat. Rev. Mater. 2020, $5,44$.

[9] Z. Wang, Q. Lin, F. P. Chmiel, N. Sakai, L. M. Herz, H. J. Snaith, Nat. Energy 2017, 2, 17135.

[10] J. Zhang, Z. Wang, A. Mishra, M. Yu, M. Shasti, W. Tress, D. J. Kubicki, C. E. Avalos, H. Lu, Y. Liu, B. I. Carlsen, A. Agarwalla, Z. Wang, W. Xiang, L. Emsley, Z. Zhang, M. Grätzel, W. Guo, A. Hagfeldt, Joule 2020, 4, 222.

[11] G. Grancini, M. K. Nazeeruddin, Nat. Rev. Mater. 2019, 4, 4.

[12] T. M. Koh, V. Shanmugam, X. Guo, S. S. Lim, O. Filonik, E. M. Herzig, P. Müller-Buschbaum, V. Swamy, S. T. Chien, S. G. Mhaisalkar, N. Mathews, J. Mater. Chem. A 2018, 6, 2122.

[13] P. Chen, Y. Bai, S. Wang, M. Lyu, J.-H. Yun, L. Wang, Adv. Funct. Mater. 2018, 28, 1706923.

[14] K. T. Cho, G. Grancini, Y. Lee, E. Oveisi, J. Ryu, O. Almora, M. Tschumi, P. A. Schouwink, G. Seo, S. Heo, J. Park, J. Jang, S. Paek, G. Garcia-Belmonte, M. K. Nazeeruddin, Energy Environ. Sci. 2018, 11, 952.

[15] J. J. Yoo, S. Wieghold, M. C. Sponseller, M. R. Chua, S. N. Bertram, N. T. P. Hartono, J. S. Tresback, E. C. Hansen, J.-P. Correa-Baena, V. Bulović, T. Buonassisi, S. S. Shin, M. G. Bawendi, Energy Environ. Sci. 2019, 12, 2192. 
[16] Y. Lin, Y. Bai, Y. Fang, Z. Chen, S. Yang, X. Zheng, S. Tang, Y. Liu, J. Zhao, J. Huang, J. Phys. Chem. Lett. 2018, 9, 654.

[17] H. Kim, S.-U. Lee, D. Y. Lee, M. J. Paik, H. Na, J. Lee, S. I. Seok, Adv. Energy Mater. 2019, 9, 1902740.

[18] D. Lin, T. Zhang, J. Wang, M. Long, F. Xie, J. Chen, B. Wu, T. Shi, K. Yan, W. Xie, P. Liu, J. Xu, Nano Energy 2019, 59, 619.

[19] Y. Liu, S. Akin, L. Pan, R. Uchida, N. Arora, J. V. Milić, A. Hinderhofer, F. Schreiber, A. R. Uhl, S. M. Zakeeruddin, A. Hagfeldt, M. I. Dar, M. Grätzel, Sci. Adv. 2019, 5, eaaw2543.

[20] D. H. Cao, C. C. Stoumpos, O. K. Farha, J. T. Hupp, M. G. Kanatzidis, J. Am. Chem. Soc. 2015, 137, 7843.

[21] C. C. Stoumpos, D. H. Cao, D. J. Clark, J. Young, J. M. Rondinelli, J. I. Jang, J. T. Hupp, M. G. Kanatzidis, Chem. Mater. 2016, 28, 2852.

[22] J.-C. Blancon, H. Tsai, W. Nie, C. C. Stoumpos, L. Pedesseau, C. Katan, M. Kepenekian, C. M. M. Soe, K. Appavoo, M. Y. Sfeir, S. Tretiak, P. M. Ajayan, M. G. Kanatzidis, J. Even, J. J. Crochet, A. D. Mohite, Science 2017, 355, 1288.

[23] J.-W. Lee, Z. Dai, T.-H. Han, C. Choi, S.-Y. Chang, S.-J. Lee, N. D. Marco, H. Zhao, P. Sun, Y. Huang, Y. Yang, Nat. Commun. 2018, 9, 3021.

[24] W. S. Yang, J. H. Noh, N. J. Jeon, Y. C. Kim, S. Ryu, J. Seo, S. I. Seok, Science 2015, 348, 1234.

[25] K. T. Cho, S. Paek, G. Grancini, C. Roldán-Carmona, P. Gao, Y. Lee, M. K. Nazeeruddin, Energy Environ. Sci. 2017, 10, 621.
[26] Y. Cho, A. M. Soufiani, J. S. Yun, J. Kim, D. S. Lee, J. Seidel, X. Deng, M. A. Green, S. Huang, A. W. Y. Ho-Baillie, Adv. Energy Mater. 2018, 8, 1703392

[27] T. J. Jacobsson, J.-P. Correa-Baena, E. Halvani Anaraki, B. Philippe, S. D. Stranks, M. E. F. Bouduban, W. Tress, K. Schenk, J. Teuscher, J.-E. Moser, H. Rensmo, A. Hagfeldt, J. Am. Chem. Soc. 2016, 138, 10331.

[28] J.-P. Sylvestre, S. Poulin, A. V. Kabashin, E. Sacher, M. Meunier, J. H. T. Luong, J. Phys. Chem. B 2004, 108, 16864.

[29] H.-D. Lee, H. Kim, H. Cho, W. Cha, Y. Hong, Y.-H. Kim, A. Sadhanala, V. Venugopalan, J. S. Kim, J. W. Choi, C.-L. Lee, D. Kim, H. Yang, R. H. Friend, T.-W. Lee, Adv. Funct. Mater. 2019, 29, 1901225.

[30] Q. Han, S.-H. Bae, P. Sun, Y.-T. Hsieh, Y. (Michael) Yang, Y. S. Rim, H. Zhao, Q. Chen, W. Shi, G. Li, Y. Yang, Adv. Mater. 2016, 28, 2253.

[31] M. I. Saidaminov, A. L. Abdelhady, B. Murali, E. Alarousu, V. M. Burlakov, W. Peng, I. Dursun, L. Wang, Y. He, G. Maculan, A. Goriely, T. Wu, O. F. Mohammed, O. M. Bakr, Nat. Commun. 2015, 6, 7586.

[32] Q. Dong, Y. Fang, Y. Shao, P. Mulligan, J. Qiu, L. Cao, J. Huang, Science 2015, 347, 967.

[33] M. M. Tavakoli, P. Yadav, D. Prochowicz, M. Sponseller, A. Osherov, V. Bulović, J. Kong, Adv. Energy Mater. 2019, 9, 1803587.

[34] G. Xia, B. Huang, Y. Zhang, X. Zhao, C. Wang, C. Jia, J. Zhao, W. Chen, J. Li, Adv. Mater. 2019, 31, 1902870. 